\title{
Pear Seeds Retain Viability after Liquid Nitrogen Immersion
}

\author{
Barbara M. Reed ${ }^{1}$, Sara Schwanke ${ }^{2}$, and Rebecca Shala ${ }^{3}$ \\ U.S. Department of Agriculture-Agricultural Research Service National \\ Clonal Germplasm Repository, 33447 Peoria Road, Corvallis, OR 97333-2521
}

Additional index words. cryopreservation, germination, liquid nitrogen, Pyrus, seed viability, TZ

Abstract. Cryopreservation in liquid nitrogen $(\mathrm{LN})$ is relatively routine for many small, desiccation-tolerant (orthodox) seeds. Seeds of Pyrus species are considered orthodox but have not been evaluated for $L N$ storage. Seeds of freshly collected $P$. communis $L$. ('Bosc') were evaluated for germinability and by TZ staining after exposure to four $\mathrm{LN}$ treatments: 1) direct immersion and direct removal; 2) direct immersion and 1 minute in $\mathrm{LN}$ vapor phase before removal; 3) 2 minutes in vapor phase before immersion and direct removal; and 4) 2 minutes in vapor phase before immersion and 1 minute in vapor phase before removal. Fresh 'Bosc' seed viability evaluated by $\mathrm{TZ}$ and greenhouse germination tests remained high $(83 \%$ to $100 \%)$ following four types of $\mathrm{LN}$ treatments, compared to the controls (77\% to $87 \%$ ). Differences in 'Bosc' seed viability were small and TZ results showed no significant differences among the $L N$ treatments. Direct $L N$ immersion and removal resulted in significantly more greenhouse-germinated 'Bosc' seeds than the other treatments and fewer control seeds germinated than any $\mathrm{LN}$ treated seeds. Fresh 'Bosc' seed cryopreserved at $7.9 \%$ moisture exhibited high germinability by both $\mathrm{TZ}$ and germination tests. $\mathrm{LN}$ exposure caused no physical damage to the seeds. Chemical name used: 2,3,5-triphenyltetrazolium chloride (TZ).

Storage temperature and seed moisture content are the most important factors affecting the longevity of stored seed. For most orthodox (desiccation-tolerant) seeds, the optimum moisture content for $-20{ }^{\circ} \mathrm{C}$ storage ranges from $4 \%$ to $7 \%$ (Stanwood and Bass, 1978). Although most cultivated pears (Pyrus communis L.) are vegetatively propagated, germplasm of wild species can be stored as seed. Cryopreservation provides long-term storage for orthodox seed and would be ideal for pear germplasm. There are no reports of Pyrus seed cryopreservation. Seeds of most common agricultural and horticultural crops are tolerant to exposure to liquid nitrogen (LN). Over 155 species and 455 selections are reported to survive LN exposure (Stanwood, 1985). Most desiccation-tolerant and LNtolerant seeds have high survival when seed moisture content is between $5 \%$ and $10 \%$ and the cooling rate is 1 to $30^{\circ} \mathrm{C} / \mathrm{min}$ to $-196^{\circ} \mathrm{C}$. If a test sample is not damaged, the whole sample can be safely stored (Stanwood, 1985). The objective of this study was to determine the effect of LN exposure on freshly collected $P$. communis cv. Bosc seeds.

Received for publication 8 Nov. 2000. Accepted for publication $16 \mathrm{Feb}$. 2001. Use of trade names in this publication does not imply endorsement of the U.S. Dept. of Agriculture. The cost of publishing this paper was defrayed in part by the payment of page charges. Under postal regulations, this paper therefore must be hereby marked advertisement solely to indicate this fact.

${ }^{1}$ To whom reprint requests should be addressed. E-mail address: reedbm@bcc.orst.edu.

${ }^{2} 1998$ ARS High School Research Apprentice, South Salem High School.

${ }^{3} 1998$ Saturday Academy Internship, Corvallis High School.

\section{Materials and Methods}

Pyrus communis 'Bosc' fruit (NCGR accession no. 1165.002; Plant Introduction No. 541387) was harvested from the National Clonal Germplasm Repository (NCGR) Pyrus field collection near Corvallis, Ore. The fruit was stored for $40 \mathrm{~d}$ in a warm area to speed decomposition, the cores were extracted by hand, and the locules were either squeezed to force the seeds out or they were placed in a blender to briefly break up the core. Pears that were extremely firm were cut transversely exposing the seeds immediately. Over 1200 seeds were extracted, allowed to dry overnight, and cleaned using a metal screen. Ten replicates of 10 seeds each were placed in aluminum foil trays, weighed, and dried in an oven for $16 \mathrm{~h}$ at $103{ }^{\circ} \mathrm{C}$ (Justice and Bass, 1978). The seeds were allowed to cool for 2 to $7 \mathrm{~d}$ in a desiccator. Moisture content (FW basis) and coefficient of variability were calculated as follows:

$\%$ Seed moisture content $(\mathrm{MC})=$

$$
\frac{\text { Fresh wt }- \text { Dry wt }}{\text { Fresh wt }}
$$

Coefficient of variability (Cv) $=$

$$
\begin{gathered}
\begin{array}{c}
\text { Standard deviation of the mean } \\
\text { moisture content } \times 100
\end{array} \\
\hline \text { Mean moisture content }
\end{gathered}
$$

Four LN immersion and seed removal methods were studied: 1 ) seeds were directly immersed (D) into LN and directly removed (D) to thaw at room temperature; 2) seeds were directly immersed (D) into LN and warmed in vapor phase $(\mathrm{V})$ for 1 min before being brought to room temperature; 3 ) seeds were equilibrated for $2 \mathrm{~min}$ in the vapor phase (V) before being immersed in LN and were directly removed (D) from LN to thaw at room temperature; and 4) seeds were equilibrated for $2 \mathrm{~min}$. in the vapor phase $(\mathrm{V})$ before being immersed in LN and were warmed in the vapor phase (V) for $1 \mathrm{~min}$ before being brought to room temperature. All seed remained in $\mathrm{LN}$ for $30 \mathrm{~min}$. Six replicates ( 3 for TZ tests and 3 for germination tests) of 10 seeds each were used for each of the $4 \mathrm{LN}$ treatments. Each 10-seed group was placed in a plastic $1.2 \mathrm{~mL}$ cryovial (Simport, Quebec), attached to metal canes, and immersed in LN. Thirty seeds were held at room temperature as a control. After the $\mathrm{LN}$ treatments were completed, the viability of the seeds was evaluated using standard germination and TZ tests.

Seeds were removed from $\mathrm{LN}$, thawed for $30 \mathrm{~min}$ at room temperature $\left(22^{\circ} \mathrm{C}\right)$, soaked in warm tap water $\left(25^{\circ} \mathrm{C}\right)$ for 3 to $4 \mathrm{~h}$, and stored between damp paper towels overnight to soften the seed coats. Seed coats were removed with fine forceps and a scalpel and the embryos placed in a $1 \%$ TZ solution for 3 to $4 \mathrm{~h}$ (DiMaio and Shillito, 1989). Seeds were evaluated using a viability scale of TZ-stained seeds we developed for pear based on seed diagrams of agronomic crops in Grabe (1970) (Fig. 1). Seeds similar to diagrams 1 to 5 were considered viable and 6 to 14 nonviable. Initial evaluation found that separation of the cotyledons at the time of seed coat removal caused surface damage to the seeds, resulting in nonviable ratings, so the cotyledons were not separated until just prior to evaluation. Data were subjected to analysis of variance and means separated using Duncan's multiple range test.

A germination test of control seed was performed to compare with the TZ viability test. A germination tray was filled with three inches of perlite soaked with tap water. Seeds were surface sterilized for $10 \mathrm{~min}$ in a $20 \%$ household bleach $(\mathrm{NaOCl})$ solution (Clorox, Oakland, Calif.), rinsed with tap water, and 30 seeds from the control and each LN treatment were planted $1 \mathrm{~cm}$ deep in the perlite. The germination trays were covered with plastic bags and placed in cold storage $\left(4^{\circ} \mathrm{C}\right)$ for 8 weeks to stratify the seed. After 8 weeks, the bags were removed and the trays transferred to a greenhouse at $20{ }^{\circ} \mathrm{C}$ with ambient light. Germination was determined after an additional 5 weeks in the greenhouse.

\section{Results and Discussion}

Mean 'Bosc' seed MC was $7.86 \% \pm 0.73$ $(\mathrm{CV}=0.93)$. This moisture content did not adversely affect the viability of pear seeds and is consistent with optimum viability for many seed types exposed to LN (Stanwood, 1985). The TZ and germination tests showed that viability of seed exposed to all four LN treatments was equal to or greater than the control seed viability. LN exposed seed viability ranged from $87 \%$ to $97 \%$ by TZ tests and $83 \%$ to $100 \%$ by germination while vi- 
Table 1. Viability and germination of 'Bosc' pear control seed and seed subjected to four liquid nitrogen immersion and removal treatments including $30 \mathrm{~min}$ exposure to liquid nitrogen $(\mathrm{LN})$ as determined by triphenyltetrazolium chloride (TZ) and germination tests.

\begin{tabular}{lccccc}
\hline \hline & \multicolumn{4}{c}{ LN immersion and removal treatments } & \\
\cline { 2 - 5 } Viability test & $\mathrm{D}^{z}$ in, D out & D in, VP out & VP in, D out & VP in, VP out & Control not frozen \\
\hline TZ $^{y}$ & $87 \mathrm{a}$ & $93 \mathrm{a}$ & $90 \mathrm{a}$ & $97 \mathrm{a}$ & $87 \mathrm{a}$ \\
Germination $^{\mathrm{x}}$ & $100 \mathrm{a}$ & $93 \mathrm{~b}$ & $87 \mathrm{~b}$ & $83 \mathrm{~b}$ & $77 \mathrm{c}$
\end{tabular}

${ }^{ } \mathrm{D}=$ direct immersion or removal from liquid nitrogen. $\mathrm{VP}=$ held in the vapor phase of liquid nitrogen for 2 min prior to immersion or $1 \mathrm{~min}$ after removal from liquid nitrogen.

${ }^{y}$ Viability evaluated according to Fig. 1 after $4 \mathrm{~h}$ in TZ. $\mathrm{n}=30$

${ }^{\mathrm{x}}$ Germinated in the greenhouse following 8-week stratification. Evaluated after 5 weeks in the greenhouse. Means in a row followed by different letters are significantly different at $P \geq 0.05$ by Duncan's multiple range test. $\mathrm{n}=30$.

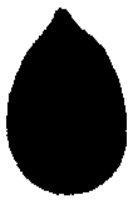

1

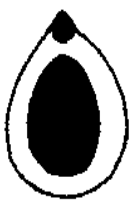

6

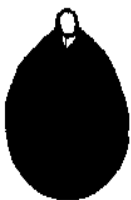

11

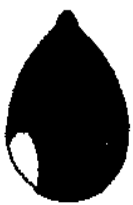

2
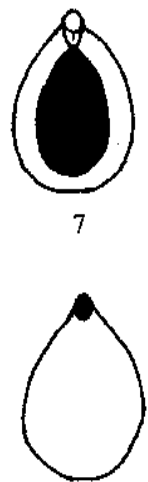

12
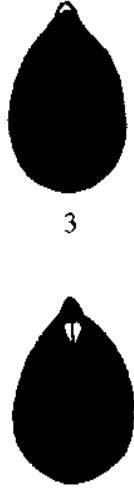

8

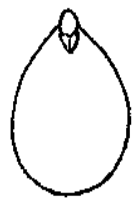

13

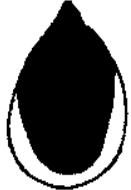

4

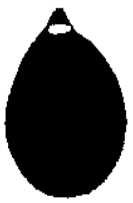

9

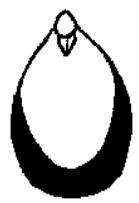

14

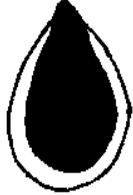

5

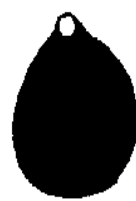

10
Fig. 1. Triphenyltetrazolium chloride staining patterns for Pyrus communis seed. Black sections indicate pink or red staining of living cell and white areas indicate dead cells. Drawings 1 to 5 illustrate germinable seeds and 6 to 14 nongerminable seeds (Developed by Schwanke from Grabe, 1970) ability of control seed was $87 \%$ by $\mathrm{TZ}$ and $77 \%$ by germination tests (Table 1). TZ test results for 'Bosc' seed following LN treatments were not significantly different for the four treatments, indicating that none of the treatments adversely affected seed viability. However, germination tests indicated that the direct submersion and removal treatment resulted in significantly better germination than any of the other treatments. All LN treated seeds germinated significantly better than the control group. LN exposure may have enhanced the germination of treated seed by further breaking seed dormancy or softening the seed coat. No seed cracking or obvious physical damage resulted from the freezing process in any of the four methods. These tests indicate that pear seeds dried to $5 \%$ to $10 \%$ moisture are similar to other orthodox seeds and can be safely stored in LN.

\section{Literature Cited}

DiMaio, J.J. and R.D. Shillito. 1989. Cryopreservation technology for plant cell cultures. J. Tissue Culture Methods 12(4):163-169.

Grabe, D.F. (ed.). 1970. Tetrazolium testing handbook for agricultural seeds, Contribution No. 29 to the Handbook on Seed Testing ed. Assn. of Official Seed Analysts.

Justice, O.L. and L.N. Bass (eds.). 1978. Principles and practices of seed storage. Agriculture Handbook No. 506 U.S. Dept. of Agr., Sci. and Educ. Admin., Washington, D.C.

Stanwood, P.C. 1985. Cryopreservation of seed germplasm for genetic conservation, p. 199226. In: K.K. Kartha (ed.). Cryopreservation of plant cells and tissues. CRC Press, Boca Raton, Fla.

Stanwood, P.C. and L.N. Bass. 1978. Ultracold preservation of seed germplasm. In: A. Sakai and P. Li (eds.). Plant cold hardiness and freezing stress. Academic, New York. 